\title{
Decadal change in tripton concentration in a shallow lake
}

\author{
Takehiko Fukushima $^{1,2}$ (D) Shunsuke Komuro ${ }^{1} \cdot$ Tatsumi Kitamura $^{1} \cdot$ Yumi Nagahama ${ }^{1} \cdot$ Bunkei Matsushita $^{2}$
}

Received: 28 July 2019 / Accepted: 12 November 2019 / Published online: 19 November 2019

(c) Springer Nature Switzerland AG 2019

\begin{abstract}
In shallow polymictic lakes where the resuspension of sediments frequently occurs, tripton (non-living particulate materials) can affect physical, chemical and biological processes. Over the last four decades, substantial changes in tripton concentrations and therefore limnological parameters have been observed in Lake Kasumigaura, a shallow eutrophic lake. To build a conceptual model of the various relationships between these, we analyzed data on monthly water and yearly sediment quality at several stations together with meteorological information. Large short-term and decadal variations were characteristics for tripton. Annual averages in tripton concentration changed substantially (e.g., from 3 to $25 \mathrm{mg} \mathrm{I}^{-1}$ at the lake center), peaking in the early 2000s, when phosphorus and silicon in water were high, and we observed a large proportion of diatoms in phytoplankton and low light penetration. Tripton concentration showed a positive correlation with sediment water content (WC) and a negative one with sediment ignition loss (IL) with a few years' delay, confirming the results of previous hydraulic experiments. Using these parameters, multiple regression models for estimating tripton concentrations were constructed and showed good performances (e.g., adjusted $r^{2}=0.61$ at the center). Furthermore, changes in inorganic ions in water, probably resulting from meteorological variations, were inferred to bring about changes in sediment WC. On the other hand, the amount of Microcystis sp. in water was suspected to govern the sediment IL. We reveal many processes (physical, chemical, biological and meteorological phenomena) related to tripton, and thus, their relationships could be considered a conceptual model for a shallow lake.
\end{abstract}

Keywords Tripton · Shallow lake · Sediments · Decadal change

\section{Introduction}

Non-living particulate materials in water are called tripton [1, 2], abioseston [1] or NPSS (non-phytoplankton suspended solids) [3]. Gons et al. [4] proposed a method for estimating the amount of tripton as the difference between suspended solids (SS) and estimated phytoplanktonic SS concentrations using chlorophyll $a$ (Chl-a) concentration assuming the dominance of phytoplankton in bioseston. In addition, the optical properties of tripton have been analyzed on filter paper after extraction with absolute methanol [5]. The light-scattering characteristics of individual tripton particles were measured by scanning electron microscopy (SEM) interfaced with automated $X$-ray microanalysis and image analysis (SAX) [6]. However, the latter two methods are rather laborious to quantify the amount of tripton in lake water on a regular basis.

Tripton affects physical, chemical and biological processes in lakes. These include light attenuation in the water column and thereby primary production, phytoplankton species [7], supply or elimination of chemicals stimulating or suppressing biological activities through adsorption,

Electronic supplementary material The online version of this article (https://doi.org/10.1007/s42452-019-1668-9) contains supplementary material, which is available to authorized users.

Takehiko Fukushima, fukushima.takehik.fu@u.tsukuba.ac.jp | ${ }^{1}$ Ibaraki Kasumigaura Environmental Science Center, 1854 Okijyuku, Tsuchiura, Ibaraki 3000023, Japan. ${ }^{2}$ Faculty of Life and Environmental Sciences, University of Tsukuba, 1-1-1 Tennoudai, Tsukuba, Ibaraki 3058572, Japan. 
desorption, and/or decomposition [6], water amenity, etc. The importance of tripton in these functions could sometimes be larger than those of other components in water, such as phytoplankton, nekton and dissolved matter.

In general, tripton is supplied to a lake through terrigenous input through influent rivers [8], resuspension of sediments $[9,10]$, dust storms in the dry interiors of nearby continents [2], autochthonous production of oversaturated mineral phase [11], etc.; meanwhile, it is lost mainly by outflow and/or deposition. Nevertheless, there have not been many studies on long-term change in tripton concentration and its cause(s)/consequence(s) on lake ecosystems.

Over the last several decades, phenomena related to tripton have been reported in Lake Kasumigaura, a shallow eutrophic lake in Japan. In the early 2000s, high turbidity was observed [12]. Changes in sediment resuspension rate [13], formation of calcite [14] and so on were suspected reasons for high turbidity [15]. Furthermore, this high turbidity probably affected silicon and phosphorus concentrations in lake water $[16,17]$, and phytoplankton species composition $[18,19]$, thus bringing about a regime shift in the ecosystem [20]. However, the changes in tripton during the last several decades have not been quantitatively assessed, and the reason(s) for variation in sediment resuspension have not been clarified.

Therefore, the purposes of the present study are (1) to describe the decadal changes in tripton in a quantitative manner; (2) to consider the influences of the changes on other water quality and ecosystem dynamics; and (3) to elucidate the mechanisms for the changes, i.e., to build a conceptual model of Lake Kasumigaura. The findings would be quite helpful for understanding the dynamics and management of water quality/ecosystem in this and other shallow lakes.

\section{Data and methods}

\subsection{Study site}

Lake Kasumigaura is the second largest lake in Japan after Lake Biwa, with a surface area of $171 \mathrm{~km}^{2}$ (Fig. 1). The lake is characterized by high turbidity and eutrophic conditions (total phosphorus [TP]: $0.084 \mathrm{mg} \mathrm{I}^{-1}$, total nitrogen [TN]: $1.01 \mathrm{mg} \mathrm{l}^{-1}$ from 1979 to 2016 at St. 1) due to its shallowness (mean depth of $3.4 \mathrm{~m}$; maximum depth of $7.3 \mathrm{~m}$ ) and intensive human activity in the watersheds [20]. Its 1426$\mathrm{km}^{2}$ catchment area (excluding the lake area) is about $30 \%$ forests, $25 \%$ paddy fields, $25 \%$ plowed field, $10 \%$ residential and $10 \%$ other.

The apparent water residence time of the lake is about 0.55 years. This lake is so shallow that vertical stratification

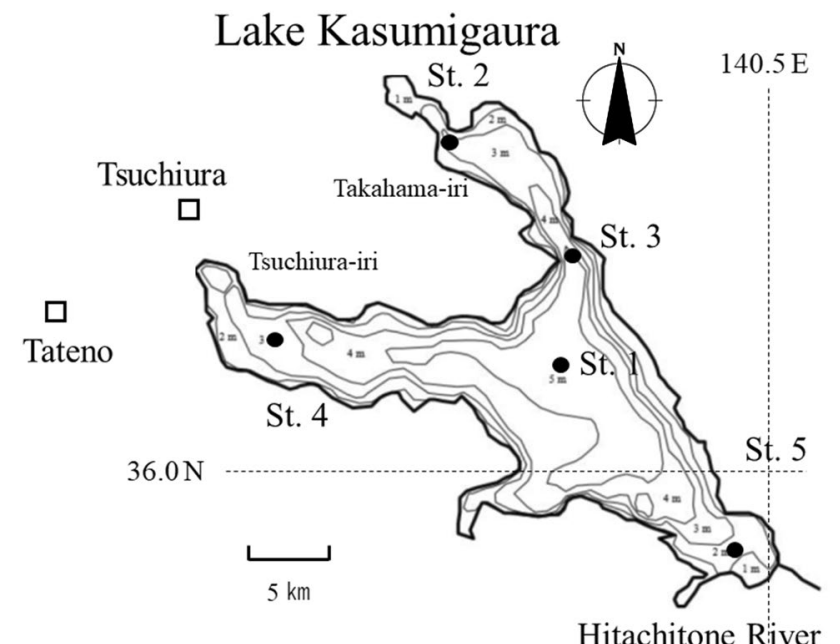

Fig. 1 Lake Kasumigaura and sampling stations. Solids circles: water quality measurement. Open squares: meteorological measurement

is easily destroyed by moderately strong winds [21]. It has two large bays: Takahama-iri and Tsuchiura-iri. Water tends to flow through the lake from northwest to southeast, to the effluent Hitachitone River. Due to its shallowness, processes related to water-sediment interactions, such as sediment resuspension, release of dissolved matter from sediments, etc., play a large role in material dynamics $[13,22,23]$. In addition, relatively rapid penetration of radiocesium into deeper sediment layers (around $20 \mathrm{~cm}$ ) was observed at the lake center a few years after the 2011 Fukushima nuclear accident [24].

\subsection{Database}

The data on monthly water quality (measured by the Kasumigaura River Office [KRO] of the Ministry of Land, Infrastructure and Transport [MLIT], National Institute for Environmental Studies [NIES] and Ibaraki Kasumigaura Environmental Science Center [IKESC]) and yearly sediment quality (measured by KRO) collected at several stations (Fig. 1) for the period 1979-2016 (2014-2019 by IKESC) were used for the analysis. KRO and IKESC took water samples $0.5 \mathrm{~m}$ below the water surface and NIES used a water column sampler (0-2 m). The annual average and sum were calculated for the data from January to December.

Of the 50 water quality parameters recorded in the KRO database, we focused on the following items: SS, Chl-a, major cations and anions (sodium $\left[\mathrm{Na}^{+}\right]$, potassium $\left[\mathrm{K}^{+}\right]$, magnesium $\left[\mathrm{Mg}^{2+}\right]$, calcium $\left[\mathrm{Ca}^{2+}\right]$, chloride $\left[\mathrm{Cl}^{-}\right]$, sulfate $\left[\mathrm{SO}_{4}{ }^{2-}\right]$ ), total silicon (TSi), TP, TN, Secchi disk transparency (SD) and COD (chemical oxygen demand). These 
were analyzed based on the JIS K 0102-2016. The data of the same items collected by NIES [25] were used to check whether or not similar tendencies could be observed. Furthermore, the data on SS, inorganic SS (ISS) and Chl-a taken at St. 1, 3, 4 and 5 by IKESC were used to verify the method of estimating tripton concentration. The concentration of ISS was determined by burning the SS filter at around $450^{\circ} \mathrm{C}$ in a muffle furnace for a few hours.

More than or equal to three sediment subsamples up to 10-cm deep were taken by bottom grab samplers (EkmanBirge type) and mixed to create one composite sample at each location and time. Sediment samplings were conducted in August (1979-2016) and February (2004-2016) and the data obtained in August were used in the following analysis. WC and IL of sediment samples were used for analysis, together with chemical concentrations, (e.g., total organic carbon [TOC] and TP). These were measured based on the procedures outlined in the sediment survey methods [26]. The averages ( \pm standard deviation) of sediment WC and IL were $(79.7 \pm 4.4 \%$ and $17.6 \pm 1.6 \%$ at St. $1 ; 75.4 \pm 5.5 \%$ and $18.0 \pm 1.7 \%$ at St. $2 ; 77.5 \pm 5.3 \%$ and $16.7 \pm 1.9 \%$ at St. $3 ; 73.6 \pm 6.3 \%$ and $14.2 \pm 2.7 \%$ at St. 4 ; $29.4 \pm 10.4 \%$ and $2.4 \pm 2.5 \%$ at St. 5) for the period investigated (1979-2016).

Meteorological information, such as precipitation and wind velocity at Tsuchiura and Tateno (Fig. 1), was used for the analysis [27]. Data on the volumes of phytoplankton [28] at St. 1 were also used to analyze the relationship between volumes of specific phytoplankton species and sediment quality.

\subsection{Calculation of tripton using Chl-a}

Tripton concentrations were estimated based on the method described in Oyama et al. [3]. Briefly, SS (concentration expressed by $C_{S S}$ ) was first assumed as the sum of tripton $\left(C_{\text {tripton }}\right)$ and phytoplanktonic SS (PSS: $\left.C_{\text {PSS }}\right)$ [4]. Phytoplanktonic SS was assumed to be proportional to $\mathrm{Chl}-\mathrm{a}$ $\left(C_{\mathrm{Chl}-\mathrm{a}}\right)$. Then, $C_{\text {tripton }}$ could be calculated as:

$C_{\text {tripton }}=C_{S S}-C_{\text {PSS }}=C_{S S}-\alpha C_{\text {Chl-a }}$

where $a$ is the proportional coefficient. Assuming that both this coefficient and the detritus concentration (= SS - phytoplanktonic SS - inorganic SS) were constant over the whole lake, the value of $a$ could be determined as the slope of the regression line (independent variable: $C_{\mathrm{Chl}-\mathrm{a}} ;$ dependent variable: organic SS concentration $\left.\left[C_{\text {OSS }}\right]\right) . C_{\text {oss }}$ was obtained by subtracting the inorganic SS (ISS: $C_{\text {ISS }}$ ) from $C_{\text {ss }}$, i.e., $C_{\text {oss }}=C_{\text {ss }}-C_{\text {ISS }}$.

Oyama et al. [3] found that $a$ was 120 using the coupled data of $C_{\text {Chl-a }}$ and $C_{\text {Oss }}\left(r^{2}=0.70\right)$ in February 18, 2006, at 25 points in Lake Kasumigaura. We used this value in the following calculations as the standard. In September 1,2009 , a different value of $a(69)$ was obtained using the same coupled data in this lake, but the correlation was rather low $\left(n=26, r^{2}=0.29\right)$. Thus, we compare and discuss the results with different values of $a$.

We note that the monitoring results used in this study were obtained under moderately weak wind conditions. Under strong winds $\left(>10 \mathrm{~m} \mathrm{~s}^{-1}\right)$, SS concentrations usually exceeded $100 \mathrm{mg} \mathrm{I}^{-1}$ [13]; however, SS concentrations rapidly declined when wind ceased. Therefore, the tripton concentrations estimated in this study seldom include the extremely high ones during strong wind periods.

\subsection{Statistical methods}

Statistical analyses were used to determine the correlation, differences between means ( $t$ test) and the multiple regression analysis for significance at the level of $p=0.05$ $\left({ }^{*}\right)$ or $p=0.01\left(^{* *}\right)$ (Excel Statistics for 2016: BellCurve Social Survey Research Information Co., Tokyo and OriginPro 2017J: OriginLab. Corp., Northampton, USA). The values of adjusted $r^{2}$ were used to select the independent parameters in multiple regression analysis. In the correlation analysis between two time series $(A(i), B(i))$, the simple correlation with time difference (j) (i.e., $A[i]$ vs $B[i-j]$ ) and the time-averaged correlation (i.e., $A[i]$ vs average of $B[i-k]: k=0-j)$ were tested.

\section{Results}

\subsection{Changes in tripton concentration}

Changes in estimated tripton concentrations with Chl-a at St. 1 are shown in Fig. 2 (1) with different parameter values of $a$. Their correlations were significant $\left(0.97^{* *}\right.$ for the original time series, $0.98^{* *}$ for 12 -mos. moving averaged time series). Therefore, hereafter we show only the results for $a=120$. Large short-term and decadal variations were characteristics for tripton (Fig. 2 (1) and Table 1), while seasonal components dominated in the variations of $\mathrm{Chl}-\mathrm{a}$, TN and TP.

Correlations among yearly averaged tripton concentrations at five stations were significant (Fig. 2 (2); $r=0.44-0.88: p<0.01$ except $r=0.39: p<0.05$ between St. 2 and 5). The differences between the maximum and minimum of yearly averaged tripton concentrations during the investigated period were larger than the means $\left(7.2 \pm 3.2 \mathrm{mg} \mathrm{l}^{-1}\right.$ [min: 3.1-max: 16.5] at St. 1; $9.7 \pm 2.6 \mathrm{mg} \mathrm{l}^{-1}[5.8-17.3]$ at St. $2 ; 7.2 \pm 2.6 \mathrm{mg} \mathrm{l}^{-1}[3.2-13.6]$ at St. $3 ; 13.5 \pm 3.4 \mathrm{mg} \mathrm{l}^{-1}[6.1-24.3]$ at St. $4 ; 11.0 \pm 3.8 \mathrm{mg} \mathrm{l}^{-1}$ [4.9-24.0] at St. 5), showing clear peaks in the early 2000s. Because the averaged phytoplanktonic SS concentrations 


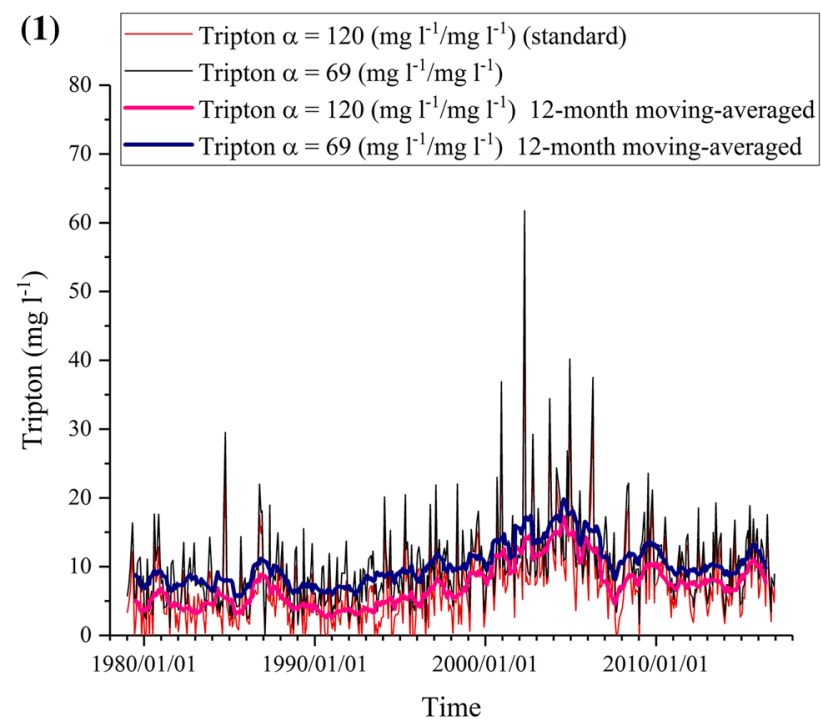

(2)

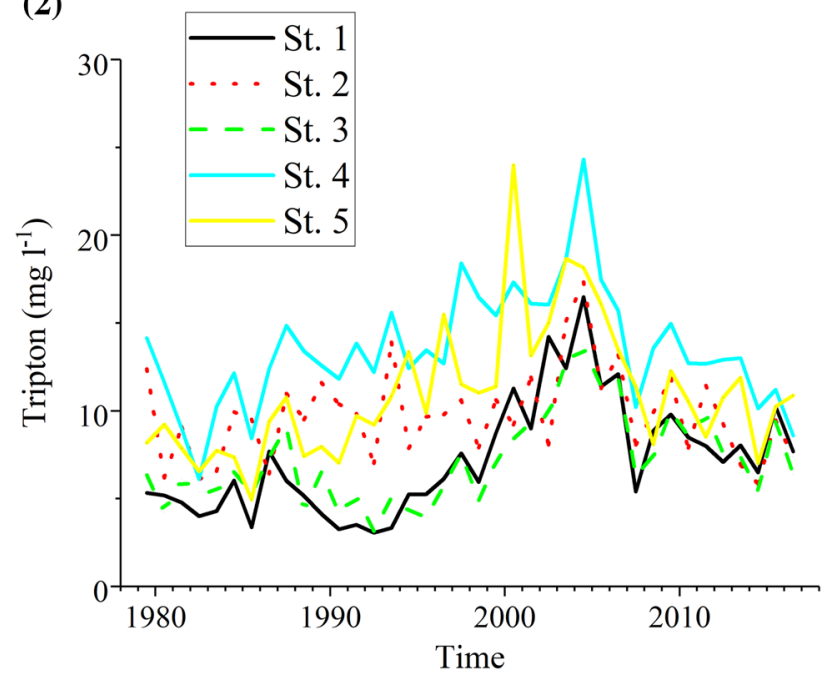

Fig. 2 Decadal changes in estimated tripton concentration with Chl-a. (1) Monthly changes and 12-month averaged changes at St. 1. Two values of $a$ were compared (see text). (2) 12-month averaged changes at 5 stations

Table 1 Proportions (\%) of water quality (estimated tripton with $a=120$, Chl-a, TN and TP) variances according to different timescales at St. 1 (total variation: 100\%). Short-term: variance of (original-3-month moving average), seasonal: variance of (3-month moving average-13-month moving average), a few years: variance of (13-month moving average-61-month moving average), decadal: variance of 61 -month moving average, others: $100 \%$-variances of above timescales

\begin{tabular}{lrllr}
\hline Time-scale & Tripton & Chl-a & TN & \multicolumn{1}{c}{ TP } \\
\hline Short-term & 44.0 & 23.9 & 23.1 & 22.7 \\
Seasonal & 24.6 & 38.8 & 33.7 & 33.2 \\
A few years & 5.2 & 10.4 & 17.2 & 5.9 \\
Decadal & 21.7 & 14.2 & 10.7 & 29.6 \\
Others & 4.5 & 12.6 & 15.4 & 8.6 \\
\hline
\end{tabular}

were $6.9 \pm 1.7 \mathrm{mg} \mathrm{l}^{-1}$ at St. $1 ; 12.7 \pm 3.2 \mathrm{mg} \mathrm{l}^{-1}$ at St. $2 ; 9.6 \pm 2.1 \mathrm{mg} \mathrm{l}^{-1}$ at St. $3 ; 7.3 \pm 1.8 \mathrm{mg} \mathrm{l}^{-1}$ at St. 4 ; and $6.8 \pm 1.5 \mathrm{mg} \mathrm{I}^{-1}$ at St. 5 , the percentages of tripton in SS ranged from 44 to $65 \%$, suggesting the importance of tripton in suspended particles.

\subsection{Tripton's influences on shallow lake ecosystem}

The peaks of TP and TSi were also observed in the early 2000s (Fig. 3), and their correlations with tripton were significant (original time series: $0.54^{* *}$ for TP; $0.41^{* *}$ for TSi; yearly average: $0.68^{* *}$ for TP; $0.74^{* *}$ for TSi). Similarly, tripton had positive correlations with SS $\left(0.85^{* *}\right)$, dissolved TP $\left(0.52^{* *}\right)$, and the proportion of diatoms volume in phytoplankton (0.64**: Supplementary Fig. 1 (1)), and negative correlations with Chl-a (-0.52**: Fig. 3$)$ and SD $\left(-0.37^{*}\right.$ : Supplementary Fig. 1 (2)) on a yearly basis. TN (Supplementary Fig. 1 (3)) and COD were not insignificantly correlated with tripton.

\subsection{Factors affecting tripton concentration and modeling}

As indicated by Seki et al. [13], tripton concentrations are governed by sediment resuspension rates. Thus, it is possible that sediment quality affected sediment resuspension rate as discussed below and subsequently tripton concentration; high WC and low IL in sediments were observed in the early 2000s (Fig. 4), indicating that tripton was positively correlated with WC and negatively correlated with IL. Considering the delay in their influence on tripton, we investigated the simple and time-averaged correlations.

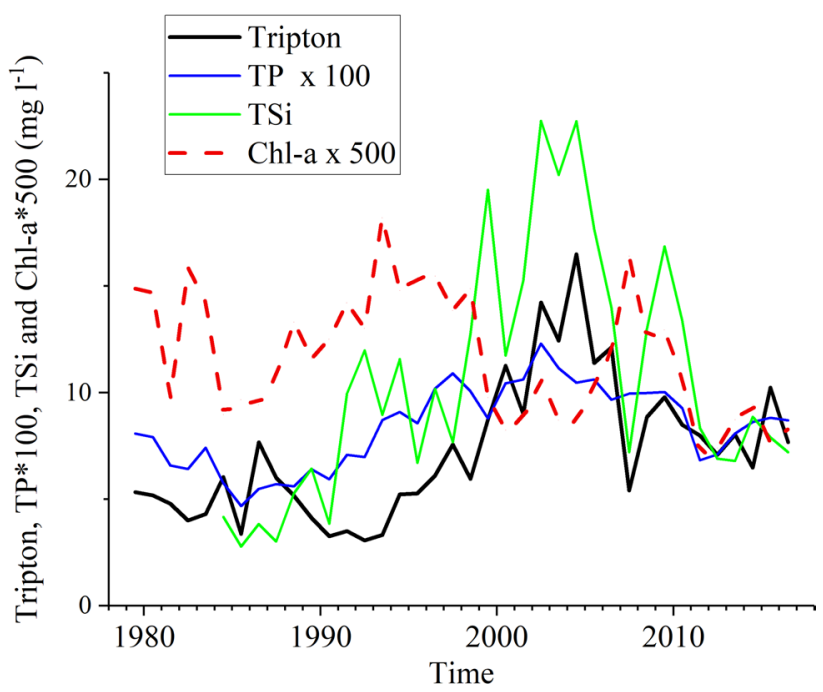

Fig. 3 Decadal changes in tripton (estimated with Chl-a and $a=120$ ), total phosphorus (TP), total silicon (TSi) and chlorophyll $a$ (Chl-a) concentrations at St. 1 


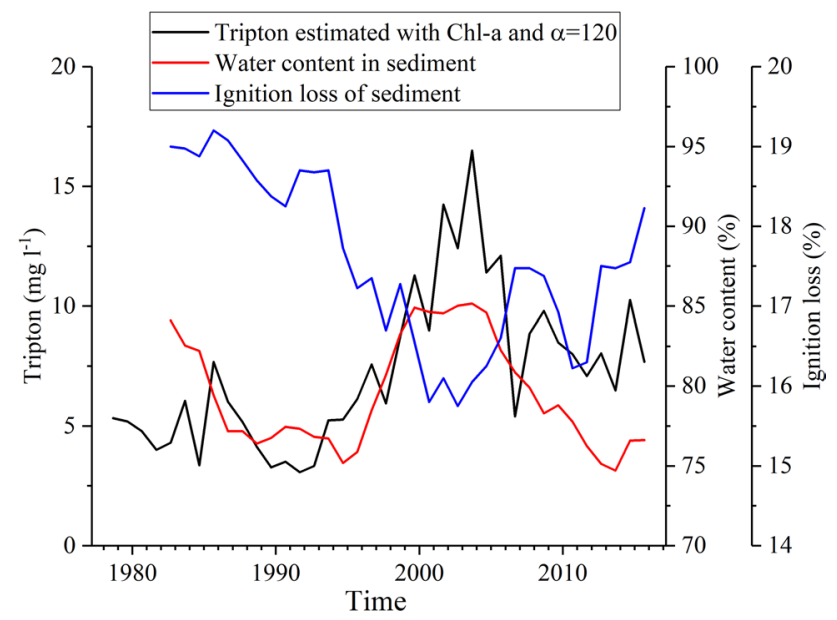

Fig. 4 Decadal changes in tripton concentration (estimated with $\mathrm{Chl}-\mathrm{a}$ and $a=120$ ), water content in sediments (average of previous 4 years) and ignition loss of sediments (average of previous 4 years) at St. 1

In the case of WC, the simple correlations were 0.26 for no delay (the same year), $0.33^{*}$ for 1 -year delay of tripton $\left(C_{\text {tripton }}[i]\right.$ vs WC $\left.[i-1]\right), 0.47^{* *}$ for 2 -year delay; $0.38^{*}$ for 3 -year delay; $0.44^{*}$ for 4 -year delay; and $-0.41^{*}$ for 5 -year delay. The time-averaged correlations were $0.50^{* *}$ for 3 -year previous average $\left(C_{\text {tripton }}[i]\right.$ vs average of WC[i-j]: $j=0,2$ ) and $0.57^{* *}$ for 4-year previous average. In the case of IL, the simple correlations were $-0.43^{* *}$ for 0 -year delay; $-0.51^{* *}$ for 1 -year delay of tripton; $-0.64^{* *}$ for 2 -year delay; $-0.52^{* *}$ for 3 -year delay; $-0.47^{*}$ for 4 -year delay; and $0.41^{*}$ for 5 -year delay. The time-averaged correlations were $-0.74^{* *}$ for 3 -year previous average and $-0.74^{* *}$ for 4-year previous average. The highest correlations were obtained for 4-year previous averaged WC and IL of sediments, respectively, at St. 1 (Supplementary Fig. 2 (1) and (2)).

Using the variables showing the highest correlations, the multiple regression model $\left(n=34, r^{2}=0.63\right.$, adjusted $r^{2}=0.61^{* *}$; Fig. 5) was constructed at St. 1 as follows:

$C_{\text {tripton }}=0.294 S_{\text {WC4yav }}-1.88 S_{\text {IL4yav }}+17.10$

where $S_{W C \text { 4yav }}$ and $S_{I L \text { 4yav }}$ are sediment WC and IL averaged for the previous 4 years, respectively. The decadal change pattern was successively described using this empirical model (Fig. 6). This model does not indicate the direct relationship between tripton concentration and sediment quality, but implies the indirect relationship between them through the medium of sediment resuspension rate.

In a similar manner using the variables showing the highest correlations, multiple regression analyses were applied to the data at other stations. Similar, but worse prediction models were obtained (adjusted $r^{2}=0.23^{* *}$,

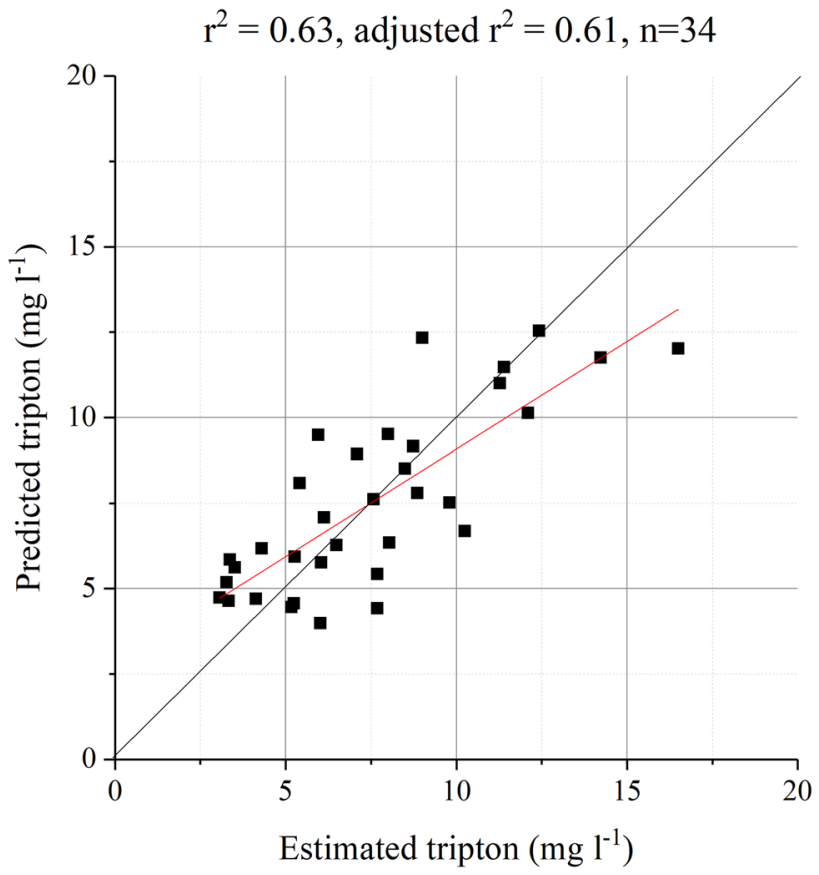

Fig. 5 Estimated with $\mathrm{Chl}-\mathrm{a}$ and $a=120$ versus predicted tripton concentrations at St. 1. Black line indicates 1:1 relationship; red line indicates the regression line

$0.41^{* *}, 0.26^{* *}$ and $0.24^{* *}$ at St. $2,3,4$ and 5, respectively. The variables showing the highest correlations were $S_{W C} 5 y$ and $S_{\mathrm{IL} \mathrm{5y}}$ at $S t .2, S_{\mathrm{WC} 5 \mathrm{y}}$ and $S_{\mathrm{IL} 4 \mathrm{y}}$ at $S t .3, S_{\mathrm{WC} \text { yyav }}$ and $S_{\mathrm{IL} 1 \mathrm{y}}$ at St. 4, and $S_{W C ~ 1 y}$ and $S_{I L ~ 4 y a v}$ at St. 5, respectively $\left(S_{W C \text { iy }}\right.$ and $S_{\mathrm{IL} \text { iy }}$ are sediment WC and IL at $i$ y before, and $S_{W C \text { iyav }}$ and $S_{\mathrm{IL} \text { iyav }}$ are sediment WC and IL averaged for the previous $i$ y). In addition, slightly better prediction models compared with the above were obtained with sediment WC and IL at

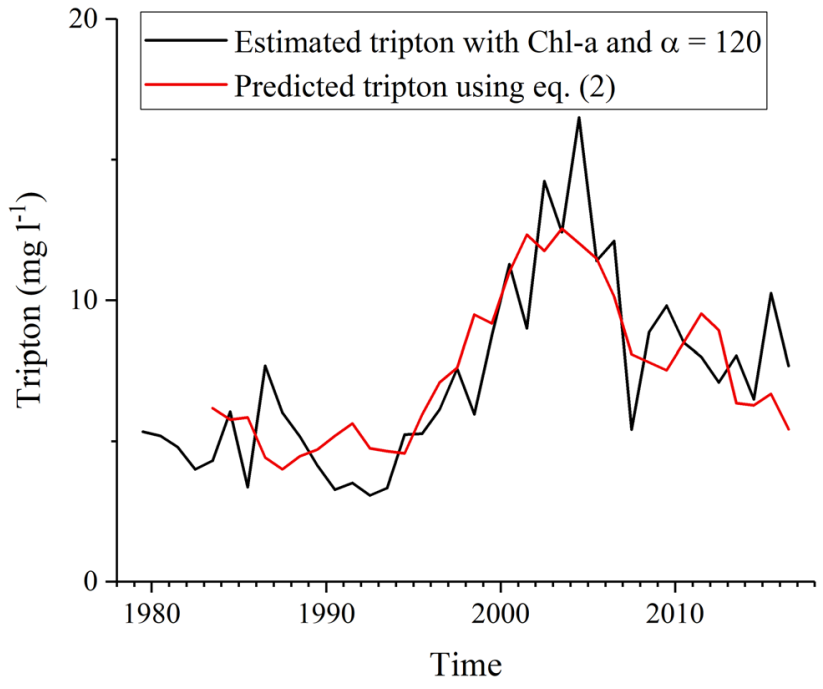

Fig. 6 Decadal changes in estimated (with Chl-a and $a=120$ ) and predicted tripton concentrations using Eq. (2) at St. 1 
St. 1 ( $S_{\mathrm{WC} \text { 4yav }}$ and $S_{\mathrm{IL} 4 \text { yav }}$ respectively) (adjusted $r^{2}=0.51^{* *}$, $0.37^{* *}$ and $0.42^{* *}$ at St. 3,4 , and 5 , respectively).

Incidentally, we did not observe significant correlations between tripton and major ion concentrations (e.g., $p>0.05$ except $r=0.40^{*}$ with $\mathrm{SO}_{4}{ }^{2-}$ at St. 1 ). Thus, the direct influence of changes in major ions on the tripton trend was not considered to be of major importance in Lake Kasumigaura [29].

\section{Discussion}

\subsection{Estimation of tripton concentration}

In this study, we used $a=120$ as a standard case for estimating tripton concentration. Seki et al. [13], using the method described above, reported $a=128.7$ based on the samples from September-December in 2004 during which time high tripton concentrations were observed. The value of $a=69$ was used for comparison, but this value was probably an underestimation because the correlation was not strong. The low correlation was possibly due to incorrect assumptions as to the constancy of $a$ and/or detritus concentration in the whole lake. Anyhow, the difference in the value of $a$ was not that important in the correlations between tripton and other water quality parameters, indicating that the characteristics related to tripton were elucidated to a considerable extent in this study.

Philps et al. [7] and Effler et al. [30] used $a=100$ based on Reynolds [31]. In addition, Kasprazak et al. [32] reported that the ratio of $\mathrm{Chl}$-a to wet weight of phytoplankton decreased as phytoplankton increased across a broad trophic gradient and that the ratio was around $0.0025-0.0030\left(\mathrm{~g} \mathrm{~m}^{-3} / \mathrm{g} \mathrm{m}^{-3}\right)$ for eutrophic lakes. Using the ratio of carbon to wet weight of phytoplankton [33] and the ratio of carbon to particulate organic matter (considered as dry weight) [34], the ratios of Chl-a to dry weight of phytoplankton, i.e., the values of $a$, were estimated to range between $81-110$ for diatoms and 98-132 for other autotrophs. These values were close to our assumed value. In future, it would be desirable to measure the tripton concentration in lake water directly and/or to confirm the assumption on constancy of $a$ and detritus concentration throughout the lake.

Next, we investigated the relationship among SS, Chl-a, OSS and ISS using the IKESC database. First, the correlation coefficients between SS and ISS $\left(r=0.89^{* *}, 0.94^{* *}\right.$. $0.94^{* *}$ and $0.91^{* *}$ at St. 1, 3, 4 and 5, respectively) were higher than those between SS and OSS $\left(r=0.52^{* *}, 0.73^{* *}, 0.54^{* *}\right.$ and $0.60^{* *}$ at St. $1,3,4$ and 5 , respectively), indicating the dominance of the variation of inorganic component in that of particulate matter in Lake Kasumigaura. With regard to the relationship between $\mathrm{Chl}$-a and OSS, significant but low correlations were obtained at the four stations

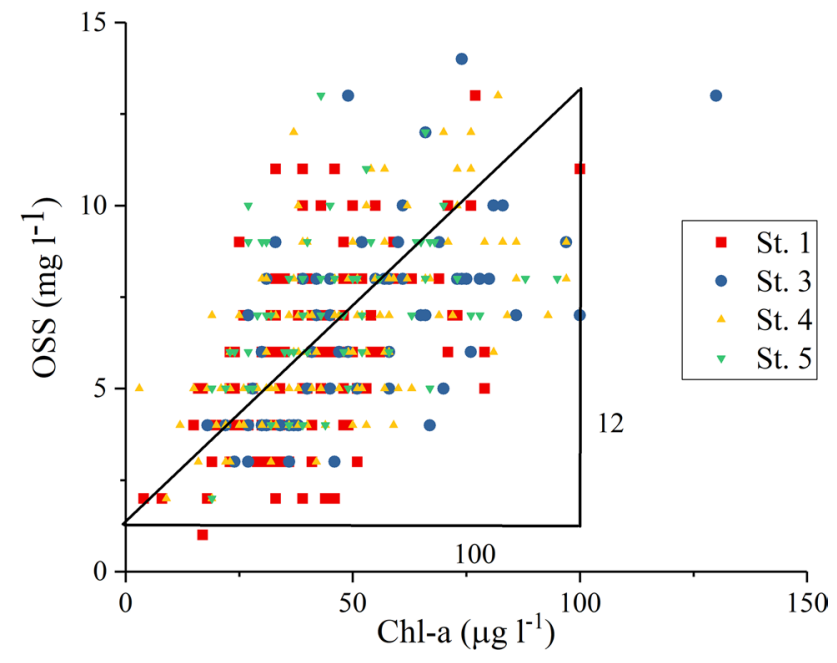

Fig. 7 Relationship between Chl-a and OSS (=SS-ISS) based on the data by IKESC. The line with the slope of $a=120$ is shown

(Fig. 7), and thus, the slopes of the linear regression lines $\left(C_{\text {OSs }}=78 C_{\text {Chl-a }}+2.7, n=124, r^{2}\right.$ adjusted $=0.26^{* *}$, St. 1 , etc.) were smaller than $a=120$. In addition, higher slopes similar to $a=120$ were obtained when the intercepts of the regression lines were set zero $(136,119,130$ and 142 at St. 1, 3, 4 and 5, respectively). Subsequently, we examined the relationships between tripton and ISS. A highly significant relationship between them was obtained at St. 1 using $a=120$ for estimating tripton concentrations (Fig. $8 ;$ St. $\left.1, r=0.89^{* *}\right)$, as well as at St. 3,4 and $5\left(r=0.93^{* *}\right.$,

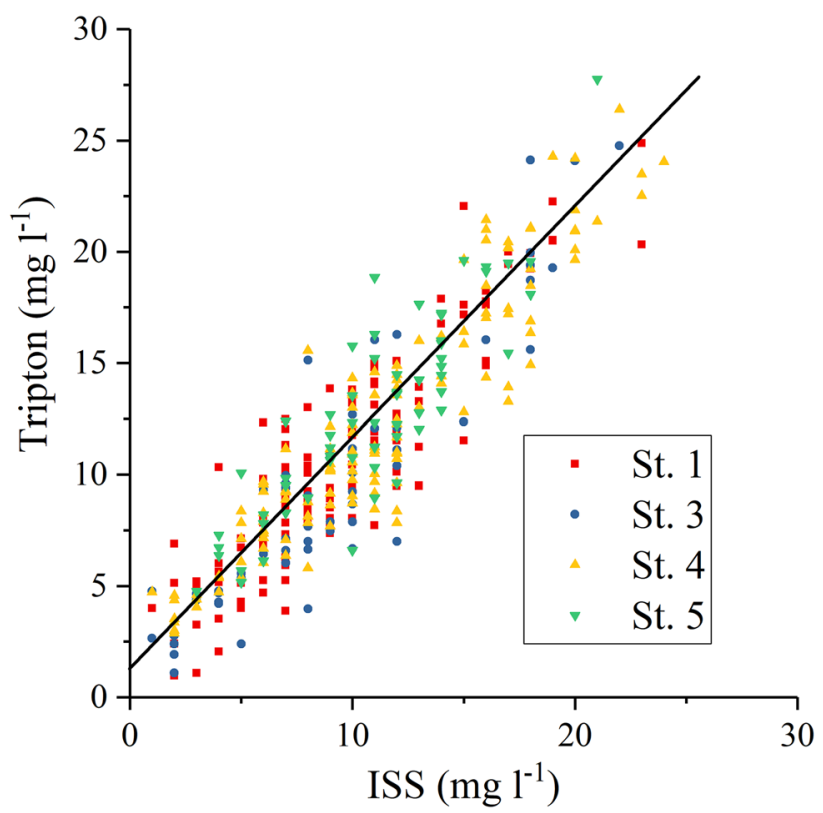

Fig. 8 Relationship between ISS and estimated tripton based on the data by IKESC $(a=120)$. The linear regression line was created using all data at four stations 
$0.91^{* *}$. and $0.87^{* *}$ at St. 3, 4 and 5, respectively). The good correlation and regression line slope fairly close to unity $\left(C_{\text {tripton }}=0.98 C_{\text {ISS }}+1.4, n=372, r^{2}\right.$ adjusted $=0.83^{* *}$; data combined from the four stations) indicate that the tripton estimation method in this study $(a=120)$ is reliable for Lake Kasumigaura and that the concentration of detritus can be estimated at around $1.4 \mathrm{mg} \mathrm{I}^{-1}$ based on the intercept of this linear regression line. In the case of $a=69$, a higher slope was obtained $\left(C_{\text {tripton }}=1.04 C_{\text {ISS }}+3.1, r^{2}\right.$ adjusted $=0.87^{* *}$; Supplementary Fig. $\left.3(1)\right)$, compared to the lower slope in the case of $a=200\left(C_{\text {tripton }}=0.87 C_{\text {ISS }}\right.$ $1.0, r^{2}$ adjusted $=0.67^{* *}$; Supplementary Fig. $3(2)$ ).

\subsection{Difference in prediction model fitness among the stations}

The best prediction was obtained at St. 1. Less good results were obtained at other stations, probably suggesting that sediment resuspension occurred to lesser extent at these stations. This was probably due to lower sediment WC and smaller wind waves compared with those at St. 1. Wind fetches are relatively long for the winds in various directions (Fig. 1), and thus, higher wind waves are expected at St. 1.

In addition, slightly better prediction models at St. 3, 4 and 5 were obtained using sediment WC and IL averaged for the previous 4 years at St. 1 as input variables. This was probably because a considerable portion of the tripton at these stations was carried from the water regions in the vicinity of St. 1.

\subsection{Causes of decadal change in tripton concentration in Lake Kasumigaura}

Utagawa and Takamura [14] suspected that the white turbid water and high turbidity observed in Lake Kasumigaura resulted from calcite formation. As shown in Supplementary Fig. 4, calcium concentration in lake water increased in the latter half of 1990s and they showed that the saturation index of calcite was high during this period. There exists a discrepancy between the periods of high saturation index of calcite and high tripton concentrations. In addition, the percentage of calcite in suspended solids was at most $15 \%$ based on chemical analysis of its elemental composition. Therefore, the high tripton concentration was not due to the formation of calcite.

We then considered the influence of sediment resuspension on decadal change in tripton concentration. In Lake Kasumigaura, sediment resuspension is principally caused by wind wave [13]. The magnitude of wind wave is determined by wind fetch and velocity. Considering the fixed station, wind velocity is the dominant factor in wind wave. Because there were not clear decadal changes in wind velocity (Supplementary Fig. 5(1) and (2)), it was suggested that the change in sediment properties could result in the decadal change in sediment resuspension.

Otsubo [35] reported that the limit of sediment particle movement in a hydraulic experiment using sediment samples obtained in Lake Kasumigaura decreased with sediment WC, indicating that water acted as a lubricant. The experiment was conducted in a pipe conduit with a rectangular cross section; an alluvial bed portion was filled with the sediment samples, and the flow speed could be varied. Based on a similar experiment, Otsubo also indicated that this limit was decreased by removing organic matter from the sediment and increased by adding agar. He considered that organic matter contributed the resistance to transport force. Righetti and Lucarelli [36] reported that the cohesive effect on critical shear stress decreased as sediment WC increased based on a laboratory experiment carried out on natural benthic sediments from three alpine lakes.

These findings support our results that estimated tripton concentration in lake water increased with sediment WC and decreased with sediment IL. The few years delay of their correlations probably resulted from the time difference between water and sediment surveys and/or the time required for tripton accumulation in lake water.

Subsequently, the question arises as to why the sediment properties changed. In the latter half of the 1990s, high inorganic ions were detected in the water, particularly $\mathrm{Na}^{+}$and $\mathrm{Cl}^{-}$(Supplementary Fig. 4). Fukushima et al. [29] reported that in a laboratory experiment $\mathrm{NaCl}$ raised water content in sediment, probably due to the swelling of clay particles. They suggested that high $\mathrm{NaCl}$ conditions were induced by saline water intrusion through the downstream gate and that this intrusion was brought about by low precipitation during the period.

With regard to sediment IL, we have analyzed how it is influenced by water quality and phytoplankton. A significant relationship was observed only between sediment $\mathrm{IL}$ and Microcyctis sp. volume in water $\left(0.36^{*}\right.$ for 0 -year delay, $0.51^{* *}$ for 2 -year previous average (IL[i] vs average of Microcystis amount [i-1] and [i-2]), $0.49^{*}$ for 3-year previous average, $0.50^{* *}$ for 4 -year previous average) (Supplementary Fig. 6). Other phytoplanktonic amounts (e.g., cyanobacteria volume) did not show a significant relationship with sediment IL. For example, chemical oxygen demand (COD) showed a positive correlation with IL, but it did not reach significance ( 0.31 for 3-year previous average).

Fallon and Brock [37] reported that decomposition appeared to be of primary importance for Aphanizomenon and Anabaena, whereas sedimentation accounted for more of the decline of Microcystis based on the field surveys in Lake Mendota. Takamura and Yasuno [38] showed 
in a sediment trap experiment in Lake Kasumigaura that the sinking rates of Microcystis sp. increased after September $\left(0.0045,0.020\right.$ and $0.24 \mathrm{~m} \mathrm{day}^{-1}$ in June-August, September and October, respectively) and that Microcystis sp. sank as detritus after being decomposed in the water column. To confirm the influence of Microcystis dominance on sediment IL, it will be necessary to compare the buried proportions of organic matter in sediments among various phytoplankton species.

\section{Conclusions and outlook}

Based on the decadal changes in estimated tripton concentrations and related parameters, the significance of concentration changes of tripton in a eutrophic polymictic lake was investigated from a limnological perspective. We showed that many processes (physical, chemical, biological and meteorological phenomena) are related to tripton, and thus, their relationships could be considered as a conceptual model in shallow lakes where resuspension of sediment frequently occurs similarly as in Lake Kasumigaura. Climate variability and change could alter the model, inducing a vulnerable water quality system. Future studies should include direct measurement of tripton concentration, verification of the processes by experiments, comparison of tripton related phenomena with other shallow lakes, etc.

Acknowledgements This work was supported in part by Grants-in-Aid for Scientific Research from the Ministry of Education, Culture, Sport, Science and Technology (MEXT), Japan (17H04475 and 17H01850). The data on lake water and sediment quality were provided by Kasumigaura River Office (KRO), Kanto Regional Development Bureau, Ministry of Land, Infrastructure, Transport and Tourism (MLIT). Monitoring data on water quality and phytoplankton were also provided by National Institute for Environmental Studies (NIES).

\section{Compliances with ethical standards}

Conflict of interest The authors declare that they have no conflict of interest.

\section{References}

1. Wetzel RG (2001) Limnology, 3rd edn. Academic Press, San Diego

2. Kirk JTO (2011) Light and photosynthesis in aquatic environments, 3rd edn. Cambridge Univ Press, Cambridge

3. Oyama Y, Matsushita B, Fukushima T, Matsushige K, Imai A (2009) Application of spectral decomposition algorithm for mapping water quality in a turbid lake (Lake Kasumigaura, Japan) from Landsat TM data. ISPRS J Photogramm 64:73-85. https://doi. org/10.1016/j.isprsjprs.2008.04.005
4. Gons HJ, Burgerwiersma T, Otten JH, Rijkeboer M (1992) Coupling of phytoplankton and detritus in a shallow, eutrophic lake (Lake Loosdrecht, the Netherlands). Hydrobiologia 233:51-59. https://doi.org/10.1007/bf00016095

5. Kishino M, Takahashi M, Okami N, Ichimura S (1985) Estimation of the spectral absorption coefficients of phytoplankton in the sea. B Mar Sci 37:634-642

6. Effler SW, Prestigiacomo AR, Matthews DA, Gelda RK, Peng F, Cowen EA, Schweitzer SA (2010) Tripton, trophic state metrics, and near-shore versus pelagic zone responses to external loads in Cayuga Lake, New York, U.S.A. Fund Appl Limnol 178:1-15. https://doi.org/10.1127/1863-9135/2010/0178-0001

7. Philips EJ, Aldridge FJ, Schelske CL, Crisman TL (1995) Relationships between light availability, chlorophyll-a and tripton in a large, shallow subtropical lake. Limnol Oceanogr 40:416-421. https://doi.org/10.4319/lo.1995.40.2.0416

8. Effler SW, Peng F, Gelda RK (2007) Size distributions and light scattering features of minerogenic particles in a stream during runoff events. J Environ Eng-Asce 133:931-940. https://doi. org/10.1061/(asce)0733-9372(2007)133:9(931)

9. Gasith $A$ (1976) Seston dynamics and tripton sedimentation in pelagic zone of a shallow eutrophic lake. Hydrobiologia 51:225231. https://doi.org/10.1007/bf00005748

10. Effler SW, Matthews DA (2004) Sediment resuspension and drawdown in a water supply reservoir. J Am Water Resour As 40:251-264. https://doi.org/10.1111/j.1752-1688.2004.tb010 23.x

11. Weidemann AD, Bannister TT, Effler SW, Johnson DL (1985) Particulate and optical-properties during $\mathrm{CaCO}_{3}$ precipitation in Otisco Lake. Limnol Oceanogr 30:1078-1083. https://doi. org/10.4319/lo.1985.30.5.1078

12. Fukushima T, Matsushita B, Yang W, Jaelani LM (2017) Semi-analytical prediction of Secchi depth transparency in Lake Kasumigaura using MERIS data. Limnology 19:89-100. https://doi. org/10.1007/s10201-017-0521-3

13. Seki T, Fukushima T, Imai A, Matsushige K (2006) Turbidity increase and sediment resuspension in Lake Kasumigaura. Proc JSCE G 62:122-134. https://doi.org/10.2208/jscejg.62.122 (in Japanese with English abstract)

14. Utagawa $\mathrm{H}$, Takamura N (2007) Specification of compounds causing white turbidity in Lake Kasumigaura. Jpn J Limnol 68:425-432. https://doi.org/10.3739/rikusui.68.425 (in Japanese with English abstract)

15. Fukushima $T$, Kawamura $S$, Seki $T$, Onda $Y$, Imai $A$, Matsushige $K$ (2005) Why has Lake Kasumigaura become turbid? Verh Internat Verein Limnol 29:732-737

16. Arai H, Fukushima T, Komatsu K (2012) Increase in silicon concentrations and release from suspended solids and bottom sediments in Lake Kasumigaura, Japan. Limnology 13:81-95. https ://doi.org/10.1007/s10201-011-0358-0

17. Arai H, Fukushima T (2012) Silicon budget of eutrophic Lake Kasumigaura, Japan. J Soil Sediment 12:1501-1507. https:// doi.org/10.1007/s11368-012-0603-0

18. Arai H, Fukushima T (2014) Impacts of long-term increase in silicon concentration on diatom blooms in Lake Kasumigaura, Japan. Ann Limnol Int J Lim 50:335-346. https://doi. org/10.1051/limn/2014027

19. Nakamura K, Aizaki M (2016) Effects of suspended solid on light attenuation in the shallow and turbid Lake Kasumigaura, Japan: long-term variation of the light attenuation mechanism. Jpn J Limnol 77:13-23. https://doi.org/10.3739/rikusui.77.13 (in Japanese with English abstract)

20. Fukushima T, Arai H (2015) Regime shifts observed in Lake Kasumigaura, a large shallow lake in Japan: analysis of a 40-year limnological record. Lake Reserv Res Manag 20:54-68. https://doi. org/10.1111/Ire.12085 
21. Muraoka K, Fukushima T (1986) On the box model for prediction of water quality in eutrophic lakes. Ecol Model 31:221-236. https ://doi.org/10.1016/0304-3800(86)90065-7

22. Havens KE, Fukushima T, Xie P, Iwakuma T, James RT, Takamura N, Hanazato T, Yamamoto T (2001) Nutrient dynamics and the eutrophication of shallow lakes Kasumigaura (Japan), Donghu (PR China), and Okeechobee (USA). Environ Pollut 111:263-272. https://doi.org/10.1016/s0269-7491(00)00074-9

23. Fukushima $T$, Kamiya $K$, Onda $Y$, Imai A, Matsushige $\mathrm{K}$ (2010) Long-term changes in lake sediments and their influences on lake water quality in Japanese shallow lakes. Fund Appl Limnol 177:177-188. https://doi. org/10.1127/1863-9135/2010/0177-0177

24. Fukushima T, Komatsu E, Arai H, Kamiya K, Onda Y (2018) Shifts of radiocesium vertical profiles in sediments and their modelling in Japanese lakes. Sci Total Environ 615:741-750. https:// doi.org/10.1016/j.scitotenv.2017.09.286

25. National Institute for Environmental Studies (NIES) (2019) Lake Kasumigaura Database, National Institute Environmental Studies, Japan. http://db.cger.nies.go.jp/gem/inter/GEMS/database/ kasumi/index.html. Accessed 1 March 2019

26. Ministry of Environment (2019) Sediment survey method. http:// www.env.go.jp/water/teishitsu-chousa/. Accessed 1 March 2019

27. Japan Meteorological Agency (JMA) (2019) Past meteorological data. http://www.data.jma.go.jp/obd/stats/etrn/. Accessed 1 March 2019

28. Takamura N, Nakagawa M (2012) Phytoplankton species abundance in Lake Kasumigaura (Japan) monitored monthly or biweekly since 1978. Ecol Res 27:837

29. Fukushima T, Komuro S, Kitamura T, Nagahama Y, Matsushita $B$ (in submission) Influence of water ionic conditions on lake sediments. SN Appl Sci (submitted)

30. Effler SW, Perkins M, Ohrazda N, Matthews DA, Gelda R, Peng F, Johnson DL, Stephczuk CL (2002) Tripton, transparency and light penetration in seven New York reservoirs. Hydrobiologia 468:213-232. https://doi.org/10.1023/a:1015285231381

31. Reynolds CS (1984) The ecology of freshwater phytoplankton. Cambridge Univ Press, Cambridge

32. Kasprzak P, Padisak J, Koschel R, Krienitz L, Gervais F (2008) Chlorophyll a concentration across a trophic gradient of lakes: an estimator of phytoplankton biomass? Limnologica 38:327-338. https://doi.org/10.1016/j.limno.2008.07.002

33. Yacobi YZ, Zohary T (2010) Carbon:chlorophyll a ratio, assimilation numbers and turnover times of Lake Kinneret phytoplankton. Hydrobiologia 639:185-196. https://doi.org/10.1007/s1075 0-009-0023-3

34. Rios AF, Fraga F, Perez FF, Figueiras FG (1998) Chemical composition of phytoplankton and particulate organic matter in the Ria de Vigo (NW Spain). Sci Mar 62:257-271

35. Otsubo K (1984) Experimental studies on the physical properties of mud and the characteristics of mud transportation. Res Rep Nat Ins Environ Stud (NIES) 42:1-177 (in Japanese with English abstract)

36. Righetti M, Lucarelli C (2010) Resuspension phenomena of benthic sediments: the role of cohesion and biological adhesion. River Res Appl 26:404-413. https://doi.org/10.1002/rra.1296

37. Fallon RD, Brock TD (1980) Planktonic blue-green-algae: production, sedimentation, and decomposition in Lake Mendota, Wisconsin. Limnol Oceanogr 25:72-88. https://doi.org/10.4319/ lo.1980.25.1.0072

38. Takamura N, Yasuno M (1988) Sedimentation of phytoplankton populations dominated by Microcystis in a shallow lake. J Plankton Res 10:283-299. https://doi.org/10.1093/plankt/10.2.283

Publisher's Note Springer Nature remains neutral with regard to jurisdictional claims in published maps and institutional affiliations. 